\title{
A CONSTRUÇÃO DO PROTAGONISMO NEGRO: A IMPORTÂNCIA DO NÚCLEO AFRO-BRASILEIRO E INDÍGENA DE ILHA SOLTEIRA (NABISA) NA FORMAÇÃO DE UMA BIÓLOGA
}

\author{
Márla Alixandre Silva \\ Universidade Estadual Paulista "Júlio de Mesquita Filho" (UNESP), Ilha Solteira, São Paulo, \\ Brasil \\ HARRYSON JÚNIO LESSA GONÇALVES \\ Universidade Estadual Paulista "Júlio de Mesquita Filho" (UNESP), Ilha Solteira, São Paulo, \\ Brasil \\ BIANCA RAFAELA BONI \\ Universidade Estadual Paulista "Júlio de Mesquita Filho" (UNESP), Bauru, São Paulo, Brasil
}

\begin{abstract}
Resumo: O número de pessoas negras com acesso ao ensino superior tem aumentado nos últimos anos, reflexo do crescimento de pessoas que se autodeclaram pretas e pardas devido às mudanças sociais e políticas nas últimas décadas. Contudo, o racismo ainda está fortemente presente nos diversos âmbitos da sociedade, inclusive em instituições de ensino superior. Pensando nisso, este artigo objetiva refletir sobre como a participação no Núcleo Afro-Brasileiro e Indígena de llha Solteira (NABISA) impactou na construção do protagonismo negro na formação de uma Bióloga a partir de narrativas da própria autora. A falta de abordagem da temática negra na graduação coloca o NABISA como uma das principais influências na construção da identidade da autora, enquanto mulher negra e profissional, demonstrando a importância de se ter espaços de crítica e reflexão social e política que impactem na formação inicial.
\end{abstract}

Palavras-chave: Núcleo Negro. Ensino Superior. Racismo. Biologia.

INTRODUÇÃO

A educação no Brasil, desde a Colônia, sempre foi excludente. Ao passo que inicialmente era usada como ferramenta para evangelizar e moldar os nativos escravizados aos modos europeus, bem como fazer a manutenção dos valores morais e religiosos dos colonos. Posteriormente, também não se educou os negros que foram trazidos para o país como escravos. Com o início das instituições superiores, a partir da vinda da família real portuguesa em 1808, não foi diferente e não se pensou na possibilidade de inserção da população negra no sistema educacional até o fim da escravatura, em 1888, mesmo que com o objetivo de tentar manter o controle dos negros libertos, dessa vez sem o uso do chicote (BARROS, 2005).

As primeiras oportunidades concretas de educação escolar e ascensão da população negra, de acordo com o Ministério da Educação (MEC), surgiram no Estado Republicano, nos anos finais do século XIX, quando o desenvolvimento industrial 
impulsionou o ensino popular e o ensino profissionalizante (SILVA; ARAUJO, 2005). Na década de 1920, houve a expansão do ensino profissional pelo interior do país, e, na década seguinte, a equiparação do ensino técnico ao curso secundário, permitindo que algumas instituições proporcionassem a escolarização profissional e superior para uma pequena parcela da população negra. Como consequência do acesso à educação, formou-se "uma nova classe social independente e intectualizada" (SILVA; ARAUJO, 2005, p.73). Essa classe, por sua vez, se mobilizou e se configurou como um mecanismo de resistência e autoproteção, servindo de base para o surgimento dos primeiros movimentos negros e das primeiras reivindicações sociais negras pós-abolição.

Desta forma, para Nascimento (1968), a educação seria peça fundamental para resolução de diversos problemas sociais que são suscitados pela ignorância, como o preconceito de cor. Portanto, para os negros:

\begin{abstract}
A educação básica, a ALFABETIZAÇÃO, viria abrir novos horizontes a essas criaturas que erram por ignorância. Com a educação primária, secundária ou profissional, abrir-se-iam novos campos de trabalho a esses que hoje, se mantém em nível trabalhista inferior, ocupandose somente dos trabalhos os mais primitivos, o que lhes traz esse complexo de inferioridade que, errôneamente, atribuem, sem discernimento, à cor (NASCIMENTO, 1968, p. 279).
\end{abstract}

Em um estudo publicado por Silva (2020), demonstrou-se que o número de pessoas negras (de acordo com a classificação do Instituto Brasileiro de Geografia e Estatística - IBGE) que frequentam o ensino superior tem aumentado, dando um salto de 10,5\%, entre os anos de 2012 e 2017, e alcançando a marca de 47,3\% de negros no ensino superior, chegando a $49,9 \%$ na rede pública e $47,0 \%$ na rede privada, em 2019 (IBGE, 2020). Em relação ao número de mulheres negras que possuem ensino superior completo, houve um aumento de 16,6\%, em 2012, para 19,7\%, em 2017, enquanto o de mulheres brancas houve uma queda de $30,2 \%$ para 27,8 , no mesmo período (SILVA, T. D., 2020).

O crescimento de pessoas negras no ensino superior pode ser reflexo do aumento de pessoas que se autodeclararam pretas ou pardas nos últimos anos, indo de 46,1\% em 2001 para 56,3\%, em 2019. Tal fenômeno pode estar relacionado à identificação racial, visto que as pessoas passaram a ter cada vez "menos temor de assumir a identidade negra" devido às mudanças sociais e políticas (SOARES, 2008, p. 116), além da adoção de ações afirmativas, que são um conjunto de medidas especiais destinadas a grupos discriminados e vitimados pela exclusão social ocorridos tanto no passado quanto no presente e que objetiva eliminar as desigualdades e segregações, onde não haja predomínio de raças, etnias, religiões, gêneros etc. (BRASIL, 2021). Como exemplo, pode-se citar a Lei de Cotas que garante uma percentagem de vagas para ingresso de negros nas instituições federais de educação superior (LEI No 12.711/2012).

Nesse cenário, escancarou-se cada vez mais as desigualdades sociais que estão diretamente relacionadas a cor ou raça da população, pois, apesar do número crescente de negros com acesso ao ensino médio, quando comparado à taxa de frequência escolar líquida, a população negra tem um percentual de 18,9\% contra $35,7 \%$ em relação a 
população branca, no ano de 2019 (IBGE, 2020). Apenas o ingresso no ensino superior não é suficiente, visto que no Brasil "os jovens negros figuram como as principais vítimas de homicídios do país" (IPEA, 2020, p. 47). Tendo ceifada sua possibilidade de ingressar ou de concluir sua formação em uma instituição de ensino superior, cada vez mais pessoas negras estão se organizando para reivindicar seus direitos como cidadãos, afetados pela carga histórica de seus antepassados escravizados no Brasil, o que evidencia um crescimento na criação de movimentos, grupos e coletivos negros nas últimas décadas.

Apesar da maior ocupação dos espaços de ensino superior pelas pessoas negras, o racismo ainda está fortemente presente nos diversos âmbitos da sociedade, se manifestando nos indivíduos, nas instituições e na estrutura social. Eu', Márla Alixandre Silva, enquanto mulher negra, estudante do curso de Bacharelado em Ciências Biológicas em uma instituição de ensino superior pública, percebo essas questões a partir da minha vivência no Núcleo Afro-Brasileiro e Indígena de llha Solteira (NABISA) e vejo a necessidade de discutir tais questões dentro da minha formação acadêmica, uma vez que a experiência no Núcleo impactou não só a minha construção pessoal identitária e, consequentemente, a minha formação como profissional da Biologia, como também me fez refletir sobre o meu espaço no ensino superior. Diante deste contexto, o presente artigo tem como objetivo refletir sobre como a participação no NABISA impactou na construção do protagonismo negro na minha formação, enquanto estudante do curso de Bacharelado em Ciências Biológicas, em uma instituição de ensino superior pública.

Desta forma, para o desenvolvimento deste artigo foi utilizada a narrativa, que implica em colocar o que foi vivido em palavras, ideias e emoções, ressignificando experiências, não apenas seguindo uma ordem cronológica e objetiva, mas também respondendo a uma estrutura lógica e subjetiva. A narrativa não se trata de um relato construído sozinho, mas sim de uma espiral polivocal, produto da intersubjetividade que convoca as vozes de outros e outras (ARIAS-CARDONA; ALVARADO-SALGADO, 2015). As autoras ressaltam que, segundo Ángel e Herrera (2011), as características da investigação narrativa estão de acordo com as diretrizes da hermenêutica, na qual não tem o propósito de explicar o objeto ou descobrir leis universais, mas sim, de compreender o objeto assim como o valor do conhecimento que ele fornece, buscando indagar sobre a possibilidade de uma abordagem do social que reconheça a especificidade dos fenômenos propriamente humanos.

$O$ ato de narrar nos leva a refletir sobre a vida e suas práticas, reverberando em constante reflexão e reorganização de sentidos de quem narra, sobre si e sobre suas narrativas. "Conhecer, a si e ao mundo, é sempre experiência vital. Em melhores palavras, a autonarrativa nos constitui" (VIÇOSA et al., 2019, p. 2), pois "ao narrarmos a nossa vida, vamos inventando e configurando o estilo de existir que escolhemos para nós, alimentando nossa autonomia para conduzirmos nossa vida" (PELLANDA; BOETCHER, 2017, p. 69). Dessa forma, quando a narrativa parte de uma mulher negra inserida em um que ambiente criado sistematicamente para excluir os seus iguais, que é o ensino superior, falar sobre a ocupação deste local se torna mais que uma autonarrativa, se configura como uma manifestação política, um ato de luta.

NABISA: CONTRIBUIÇÕES DO NÚCLEO

Inter-Ação, Goiânia, v.46, n.3, p. 1413-1428, set./dez. 2021. Disponível em: <http://dx.doi.org/10.5216/ia.v46i3.67957>. 
O NABISA, fundado em 2016, inicialmente como Projeto Anastácia, é um núcleo que se originou a partir do Núcleo Negro Unesp de Pesquisa e Extensão (NUPE) com a proposta de (re)afirmar a cultura Africana e Afro-Brasileira como parte constituinte da história do Brasil. Posteriormente, o núcleo abarcou a causa indígena, visto que esta também é uma cultura que necessita ser constantemente (re)afirmada, por contribuir significativamente para a construção da cultura do povo brasileiro e trazer ainda as marcas dos preconceitos e violências do Brasil Colônia, assim como a dos povos negros. Meu contato com o núcleo foi por meio de um dos meus professores que trazia muito a questão identitária para as suas aulas, sobretudo a nossa identidade profissional, uma vez que estávamos em um curso superior, estudando para exercer uma profissão. Por se tratar de um núcleo de pesquisa e extensão, o NABISA se pautava em reunião para estudos, com leituras e discussões de textos sobre a temática étnico-racial e também organização e desenvolvimento de ações voltadas tanto para a comunidade acadêmica, como para a comunidade local.

Meu ingresso no núcleo se deu no ano de 2016, logo após a sua fundação, e cheguei a participar de algumas discussões sobre a criação do mesmo. A vontade de integrar esse espaço de discussão, quando ainda denominado "Projeto Anastácia", veio do meu contato com a temática de minorias, proporcionado por um professor da graduação. Na época, eu era voluntária no projeto de Equoterapia, outro projeto de extensão desenvolvido dentro da universidade em parceria com a Associação de Pais e Amigos dos Excepcionais (APAE), que atende pessoas com deficiência e tem o cavalo como auxiliador nas terapias desenvolvidas. A partir desse projeto, minha visão para com o outro se transformou e me fez querer entender as questões relacionadas às diversidades. Mas meu contato de fato com as questões étnico-raciais se deu em um trabalho realizado em uma disciplina da graduação, que tive que estudar e apresentar sobre a cultura do povo lorubá, e me encantei com a riqueza de elementos da cultura desse povo, além de identificar alguns deles em nossos costumes, uma vez que esse foi um dos povos trazidos para o Brasil para serem escravizados. Dessa forma, quando soube da criação do núcleo, de imediato me interessei em participar.

Nascida e criada em uma família negra com poucas condições financeiras, vivenciei muitos casos de racismo. A não aceitação do cabelo crespo ainda é fortemente presente na minha família, quando criança, por vezes, presenciei minhas tias alisarem os próprios cabelos com ferro quente e, posteriormente, utilizarem químicas fortíssimas ainda na tentativa de alisar os cabelos, antes mesmo de surgir a tal escova progressiva. Eu, que tenho cabelos cacheados, hoje em dia mais aceitos na sociedade, já escutei diversas vezes que eu deveria alisar o cabelo e a "sugestão" vinha acompanhada da piadinha de que meu cabelo era "igual bandido, quando não está preso, está armado" e ainda hoje me perguntam se não dói quando eu o penteio.

Uma vez, em um evento tradicional da cidade onde resido, presenciei o meu primo, preto, ser espancado por policiais, ele estava parado na frente do seu próprio carro com sua namorada, apreciando o evento, quando foi brutalmente abordado. Após o acontecimento ele tentou denunciar os responsáveis, mas a investigação não foi para frente, consequentemente, meu primo desenvolveu crise profunda de depressão e síndrome do pânico, só após anos de tratamento profissional e apoio da família, ele 
conseguiu se restabelecer. A partir das minhas vivências, a minha identificação com o núcleo se firmava cada vez mais, em cada discussão uma tomada de autoconsciência aflorava e o desejo de que outras pessoas negras ou de qualquer outra minoria não passassem pelo que passei se fazia presente, por isso passei a me dedicar ao grupo juntamente à minha graduação.

Desde então, o NABISA me apresentou um universo que para mim era desconhecido, me proporcionou experiências inimagináveis, me ajudou a desconstruir muitos "pré-conceitos", me apresentou pessoas incríveis e passou a ser parte da minha formação, enquanto mulher negra e acadêmica, me instigando a entender cada vez mais sobre diversas temáticas que perpassam as questões étnico-raciais, inclusive dentro do meu próprio curso.

Nas reuniões de estudo comecei a ter contato com escritas sobre questões étnico-raciais, as mais variadas possíveis, como na área da Educação, na área da Saúde, heranças culturais, dentre outras temáticas. $E$ foi a partir desse momento que comecei a relacionar o que eu lia com a minha realidade e as minhas vivências. Além dos estudos, o núcleo desenvolveu e participou de dezenas de atividades desde sua fundação, cada qual com objetivos específicos, por vezes com públicos direcionados. Dentre essas atividades foram realizados saraus, feiras culturais, cine-debates, oficinas, palestras, cursos de extensão e minicursos, tanto para a comunidade local, quanto para a comunidade acadêmica, levando a discussão para servidores, estudantes, professores tanto de outros cursos de graduação como também da educação básica.

Em algumas dessas experiências, a consciência do racismo estrutural presente na nossa sociedade se fez consciente e essa tomada de consciência me fez avaliar muitos aspectos da minha vida, olhar com mais atenção ao meu redor, às pessoas com quem eu convivo, quais cargos elas ocupam, quantos amigos negros eu tinha na minha turma, quantos docentes negros me davam aulas, comecei a ouvir mais as pessoas e seus relatos corroboravam o que eu havia estudado. Por vezes presenciei discursos racistas de pessoas negras, revelação de pessoas que não sabiam reconhecer as situações racistas pelas quais passavam, afirmações de que o racismo não existe, ou que o negro se faz de vítima para conseguir benefícios, até mesmo discursos meritocráticos de negros bem-sucedidos com a famosa frase "se eu consegui, você também consegue, é só querer", desconsiderando a realidade de cada um e os obstáculos sociais presentes, muitos deles gerados graças ao sistema capitalista regente, que tem a meritocracia como um pilar e reflete diretamente nas questões étnico-raciais. Além do cruel mito da democracia racial no Brasil, que diz que não existe racismo no país, apagando a cor das pessoas que sofrem graças às desigualdades sociais existentes, reforçados pelo próprio sistema. Emocionei-me com relatos de rejeição e histórias de autoaceitação, bem como de autorreconhecimento como pessoa negra, que é fundamental para a construção da consciência do nosso lugar de direito na sociedade e a importância da reivindicação dos espaços que foram privados de serem ocupados pelo povo negro.

Certa vez, enquanto desenvolvia uma ação do NABISA em uma escola de ensino médio, alunos negros que estavam prestes a prestar o vestibular questionaram as cotas raciais para as universidades, pois acreditavam que elas eram uma forma de afirmar que eles eram menos inteligentes que os alunos brancos. Ali eu tive a oportunidade de desmistificar essa ideia equivocada e mostrar que, na verdade, o povo negro foi e é inferiorizado, por isso a necessidade de um mecanismo que os coloquem em um 
patamar no qual disputem com menos desigualdade uma vaga no ensino superior. Em outro momento, em uma instituição de ensino de nível médio, foi realizado um cinedebate com base em um filme no qual uma menina negra sonhava em ser paquita, mas, apesar do seu excelente desempenho no teste, foi reprovada, evidentemente por ser negra. Durante a discussão, uma aluna concluiu que, por vezes, o sonho de uma pessoa negra em seguir uma carreira específica morre ainda mesmo na infância. Após a fala dessa aluna, o silêncio na sala se fez ensurdecedor e, para Silva (2012), o silêncio opera sistematicamente para ocultar processo social de desigualdade social, seja para estabelecer o branco como norma de humanidade, seja para negar a existência plena ao negro, invisibilizando-o.

Um episódio que mostra como a discussão sobre racismo na universidade deveria perpassar pelas diversas áreas do conhecimento, e não apenas a área de humanas, foi quando uma república local se autodenominou "Senzala". Seu logo era simbolizado por correntes formando um círculo que se fechava em algemas trancadas no topo da imagem, ao centro trazia a figura do Saci, ser folclórico brasileiro. O uso das correntes com algemas e o emprego da palavra senzala na nomeação da república mostra o quão banalizada foi, e ainda é, a escravidão no Brasil. O esvaziamento do peso do significado dos elementos utilizados é um ato recorrente em que não se tem discussões acerca do racismo, da herança histórica de subjugação de raças herdada pela população brasileira. E o NABISA se mostrou essencial na tentativa de conscientização das pessoas envolvidas na criação da república, pois, após um encontro entre os membros do núcleo com os moradores da casa, eles se retrataram publicamente e disseram não terem tido a intenção de usar de forma leviana símbolos tão importantes para a luta negra, alterando então o nome e o logo da república.

Dentre muitas outras experiências vivenciadas, um relato muito marcante foi de um encontro com profissionais da educação, no qual uma professora do ensino infantil relatou que, em determinado momento de seu trabalho docente com crianças de cerca de cinco anos de idade, uma menina negra disse a ela que não gostava da própria cor da pele. Sensibilizada pela situação, a professora relatou que buscou em seus métodos mostrar para a criança que não havia vergonha nenhuma em ser negra. Trago também o caso de um professor negro de uma instituição superior de ensino do estado de São Paulo, ativista das causas negras, que foi esfaqueado no dia 20 de novembro, enquanto participava de um ato em celebração da data, que é exatamente o Dia da Consciência Negra, felizmente o professor não saiu gravemente ferido fisicamente, mas as marcas deixadas no seu subconsciente podem ter sido mais profundas. Esse fato, mais uma vez, reforça como o racismo está em todos os âmbitos da sociedade. A negação da criança em aceitar a própria cor e o ataque ao professor negro que luta por seus direitos são resultados de uma construção social acerca da imagem do negro, que foi - e é reforçada constantemente - como algo ruim, tanto explicitamente como de modo sutil, configurando o racismo individual e institucional. Segundo Hamilton e Kwane (1967):

O racismo é aberto e encoberto. Ele assume duas formas intimamente relacionadas: brancos individuais agindo contra negros individualmente, e atos de toda a comunidade branca contra a comunidade negra. Chamamos isso de racismo individual e 
SILVA, M. A.; GONÇALVES, H. J. L.; BONI, B. R.

\begin{abstract}
racismo institucional. $\mathrm{O}$ primeiro consiste em atos manifestos de indivíduos, que causam morte, ferimentos ou destruição violenta de propriedade. Este tipo pode ser gravado por câmeras de televisão; pode ser frequentemente observado no processo de comissão. $\mathrm{O}$ segundo tipo é menos aberto, muito mais sutil, menos identificável em termos de indivíduos específicos que cometem os atos. Mas não é menos destrutivo para a vida humana. O segundo tipo se origina na operação de forças estabelecidas e respeitadas na sociedade e, portanto, recebe muito menos condenação pública do que o primeiro tipo (HAMILTON; KWANE, p. 171, 1967, tradução nossa).
\end{abstract}

O racismo institucional, tendo as instituições como a materialização de uma estrutura social que, por sua vez, é racista, é mais difícil de ser percebido, pois é regido por uma estrutura social previamente existente (ALMEIDA, 2018) e acaba se tornando mais difícil de ser identificado e combatido. Contudo, ter consciência da sua existência nos permite reconhecê-lo e mudar nossa postura e ações perante a situação, não só nós, sujeitos pertencentes a esse círculo social, mas também os órgãos oficiais que detêm o poder de ditar as normas que devemos seguir para manter a ordem social. A adoção de uma prática de ensino que combata o racismo, como a desenvolvida pela professora citada anteriormente, bem como a criação da Lei 10.639/03 - que estabelece como obrigatória a inclusão da temática "História e Cultura Afro-Brasileira" no currículo oficial da Rede de Ensino, nas instituições públicas e particulares de nível fundamental e médio e que, posteriormente, foi acrescentada a obrigatoriedade do ensino da história e cultura Indígena pela Lei 11.645/08 - são exemplos de ações que foram tomadas na tentativa de mudar essa realidade.

Apesar da existência da Lei 10.639/03, em muitos eventos que o NABISA realizava, principalmente naqueles voltados para educadores e educadoras atuantes ou em formação, era muito comum ouvir o relato de que não sabiam da existência dessa lei e, após descobrirem a mesma, muitos diziam que quando tentavam trabalhar estas questões em sala de aula eram confrontados pelos pais dos alunos ou até mesmo pela direção da instituição e que se apegavam à legislação para justificar suas atividades. É evidente que, mesmo com um documento que obriga os profissionais da educação abordarem a temática, na prática a situação é outra. A partir dos relatos de algumas profissionais da educação, foi possível perceber que há quem nem saiba da existência dessa obrigatoriedade, o que corrobora Medeiros (2015, p. 84) que afirma que "muitos estabelecimentos de ensino públicos e privados sequer abordam a temática proposta nas salas de aula" e ainda parece haver quem trabalhe, mas a partir de uma abordagem que acaba reforçando os estereótipos raciais, e pouco colaboram para a problematização e desconstrução da estrutura racista da nossa sociedade.

\title{
A CIÊNCIA E O RACISMO
}

Apesar de sermos capazes de perceber o racismo mais facilmente em "piadas" do cotidiano ou em situações corriqueiras do dia-a-dia, o racismo não é nutrido apenas por racionalismos. Não existe racismo se não embasado teoricamente (ALMEIDA, 2018), portanto, tão importante quanto as narrativas da cultura popular para a criação do imaginário, são as teorias científicas. No século XIX, o homem começou a indagar as 
diferenças humanas - cientificamente - na tentativa de justificar a suposta inferioridade de um povo em relação ao outro. Áreas do conhecimento como a Biologia e a Física foram utilizadas para tentar explicar a diversidade humana, dando origem ao determinismo biológico e ao determinismo geográfico, que trazem a ideia de que as raças tinham diferenças morais, intelectuais, psicológicas, determinadas por características biológicas ou por condições climáticas e/ou ambientais. Deste modo, associavam a pele não-branca e o clima tropical com o favorecimento de comportamentos imorais, lascivos e violentos (ALMEIDA, 2018).

Em seu livro Racismos, Bethencourt (2018) traz alguns autores que contribuíram com o racialismo científico. Um autor influente foi Arthur Gobineau (1816-1882), autoproclamado Conde de Gobineau e considerado um dos mais importantes teóricos do racismo no século XIX. Publicou um longo ensaio, denominado Essai sur l'inégalité des races humanies (1853-1855), que reforçava a visão latente da época de que as raças eram inatas e imutáveis. Gobineau condenava a mistura de raças, pois para ele:

[...] a mistura de raça facilitava a difusão da civilização, do mais forte para o mais fraco, ao mesmo tempo que continha as sementes da degeneração devido a inevitável submersão das elites (ou raças superiores) nos padrões mais baixos das massas (ou raças inferiores) (BETHENCOURT, p. 383, 2018).

Afirmava também que as raças consideradas selvagens sempre haviam sido selvagens, continuando a ser assim até desaparecerem, reproduzindo a ideia da bestialidade das raças negras ao evidenciar a inferioridade da raça a partir de vestígios fósseis, ideia que não demorou a ser refutada por outros estudiosos, assim como a ideia da degeneração racial.

No mesmo período, o biólogo naturalista Charles Darwin (1809-1882), declarado abolicionista, quando jovem, viajou ao redor do mundo por cinco anos observando e descrevendo tudo o que via na natureza, inclusive outros seres humanos. Em sua obra $A$ origem das espécies, Darwin refutou a ideia de que as raças são inatas e imutáveis a partir de sua teoria da seleção natural, bem como argumentou que a miscigenação não levaria à degradação de uma determinada raça, mas a evolução dos seres, contribuindo certamente para a criação de uma nova estrutura científica, o que "obrigou a adaptação dos preconceitos relativos à ascendência étnica e às construções raciais" (BETHENCOURT, 2018, p. 408). Contudo, apesar da ideia de um escravo natural não ser mais sustentável, o conceito hierárquico da seleção natural e da inferioridade dos não aptos, tomou seu lugar, dando espaço para o "darwinismo social", que aplicava as leis da teoria da seleção natural à vida da sociedade humana, dizendo que viver é uma luta "natural" pela vida, portanto seria "normal que os mais aptos a vençam, ou seja, tenham sucesso, fiquem ricos, tenham acesso ao poder social, econômico e político; da mesma forma, é normal que os menos aptos fracassem" (BOLSANELLO, 1996, p. 154). O fato de Darwin ter trazido o ser humano para o plano natural não mudou a visão dos povos "civilizados" para com os "selvagens" na natureza, uma vez que os absurdos jardins zoológicos humanos se tornaram extremamente bem-sucedidos para entretenimento. 
SILVA, M. A.; GONÇALVES, H. J. L.; BONI, B. R.

Apesar do destaque destes dois pensadores influentes, outros autores das ciências naturais contribuíram para a construção e manutenção estrutural e individual do racismo. No caso de Darwin, mesmo refutando teorias racistas dominantes no período teve seus conceitos aplicados equivocadamente para reforçar o racismo latente na sociedade da época, pois o olhar para as teorias científicas nunca é neutro, sempre é influenciado pelo contexto histórico, social e político da época. Apesar desta volatilidade, evidencia-se que "a ciência tem o poder de produzir um discurso de autoridade, que poucas pessoas tem a condição de contestar, salvo aquelas inseridas nas instituições em que a ciência é produzida", sendo muito bem pautado por teorias racistas "o racismo é, no fim das contas, uma forma de racionalidade" (ALMEIDA, 2018, p. 54).

Apesar de o racismo ser pautado cientificamente, dentro do curso que trabalha teorias que serviram de subsídio para o discurso racista, que foi o Bacharelado em Ciências Biológicas, não me recordo de presenciar alguma aula que abordasse essa temática, que ao menos citasse as distorções que uma teoria científica pode sofrer e qual o impacto disso no desenvolvimento da ciência e na sociedade como um todo. É nos ensinado a produzir conhecimento científico, mas não nos foi ensinado a levar em consideração quais as possibilidades de aplicação desse conhecimento, ou mesmo como tentar prevenir essas leituras errôneas, já que isso é passível de acontecer. Meu conhecimento sobre autores que colaboraram com teorias racistas se deu através do NABISA, e como profissional da Biologia, mulher negra e estudante em uma instituição pública de ensino superior em um país miscigenado, acredito ser de suma importância abordar essa questão também na graduação, não apenas no ensino básico, que tem a obrigatoriedade garantida por lei.

Azevedo (1987) denuncia em seu livro Onda negra, medo branco como que a educação superior corroborou a consolidação do racismo no Brasil e como ele teve o amparo das instituições científicas para se fortalecer e se concretizar dentro de uma sociedade tão miscigenada, mas com predominante pensamento colonizado, como a Escola Politécnica, o Museu do Rio de Janeiro e a Academia de Medicina do Rio de Janeiro, por exemplo. Em 1878, essa última instituição aprovou "com distinção" uma tese, em que "alertava para o fato de que não se deveria almejar tão-somente o progresso material, mas também o moral e intelectual, o que tornava sumariamente necessário examinar 'qual o povo que melhor nos convém...' E certamente não seriam os africanos" (AZEVEDO, 1987, p. 73).

Como destaca Almeida (2018), a educação é capaz de aprofundar o racismo na sociedade. É uma ferramenta muito eficiente de manutenção da sociedade, um meio de difundir ideias e valores de interesse de uma pequena elite que possui o poder de reger normas educacionais, por vezes, não passíveis de questionamentos. Mas a educação também pode ser um meio para mudar a estrutura social, visto que a educação é a base em que se ergue os pilares da sociedade, seja ela formal ou informal, e quando a educação se dá de modo a instigar a criticidade no aluno, ela é libertadora (FREIRE, 1987).

ALGUMAS CONSIDERAÇÕES 
A partir de toda experiência que influenciou a construção da minha identidade negra, da consciência de que carrego todo esse legado histórico, dos meus estudos e vivências, meu olhar sobre mim e para com o outro se transformou. Essa transformação me despertou a necessidade de discutir a importância da minha formação acadêmica, pois como bióloga, inserida em um meio que tem o poder de produzir discursos de autoridade, moldando o comportamento social, como visto ao longo da história da ciência, trago comigo a responsabilidade de não ser conivente com a sustentação da estrutura racista da nossa sociedade. Mesmo ocupando os espaços que ocupo, a imagem do negro que construí, desde o início da minha vida, a partir de elementos sociais me trazem receios e inseguranças, pois não se é acostumado a ver negros em postos elevados, por ser contestada o tempo todo, por duvidarem da sua capacidade, apenas pela sua cor de pele. Eu, ainda por ser mulher, às vezes essas contestações me fazerem duvidar de mim mesma, mas trabalho constantemente para que isso se torne $o$ meu combustível para não desistir da luta.

Como já apresentado anteriormente, o racismo está nos diversos âmbitos sociais e também nas instituições de ensino superior, mas o olhar crítico que desenvolvi, ao longo da minha trajetória acadêmica, vai moldar minha atuação em qual seja a área que eu me especialize, já que a atuação na área da Biologia é ampla e cheia de possibilidades. No caso de um licenciamento ambiental em áreas onde vivem comunidades tradicionais, por exemplo, meu olhar para com essas comunidades pode influenciar na minha avaliação e parecer final. Sem dúvida, a maior influência na construção da minha identidade foi o NABISA, visto que durante as aulas da graduação era escassa a discussão ou abordagem sobre questões étnico-raciais, salvo por um ou dois professores. Inclusive, a predominância de professores brancos e majoritariamente do gênero masculino dentro da universidade, ainda é notória. Neste aspecto, o incentivo, por parte do profissional da educação, ao aluno buscar se inserir nos espaços de discussão que se constroem para além do que é ensinado em sala de aula, é muito importante para uma formação integral do sujeito.

Há quem diga que no curso de Bacharelado em Ciências Biológicas não cabe discutir sobre questões raciais, pois isso tem que ser discutido em cursos de Ciências Humanas - por se tratar de relações humanas construídas historicamente. Contudo, acredito que se na formação destes profissionais, abordagens acerca de como as ciências naturais, que originou as Ciências Biológicas hoje, influenciaram diretamente na construção e manutenção da atual sociedade racista, esse discurso talvez seria usado com menor recorrência. $E$ é justamente essa falta de abordagem acerca das questões étnico-raciais que trago para reflexão, visto que algumas das teorias mais conhecidas da área, como a Teoria da Seleção Natural, bem como outras frentes, como a Genética, por exemplo, podem e são usadas por grupos de pessoas para justificar a superioridade de um grupo sobre outro, distorcendo dados científicos ou os interpretando de maneira errônea, carregada de preconceitos.

Para quem mantém o discurso de que nas Ciências Biológicas não se cabe discutir questões étnico-raciais, Silva (2020. p. 346) relata que "venho atuando como docente do curso de Licenciatura em Ciências Biológicas e tenho aproveitado a oportunidade para trabalhar a saúde da população negra de forma interseccional com a 
SILVA, M. A.; GONÇALVES, H. J. L.; BONI, B. R.

disciplina Biologia Celular", que é inclusive matéria componente do curso de bacharelado, pautando-se na Lei 10.639/2003 que orienta ações para educação das relações étnico-raciais, discutindo também a origem da humanidade na África a partir de aulas sobre mitocôndrias, dentre outros assuntos.

Como já dito pelo Patrono da Educação Brasileira, Paulo Freire (1992), não se é possível separar a educação do contexto social:

\begin{abstract}
E não se diga que, se sou professor de Biologia, não posso me alongar em considerações outras, que devo apenas ensinar biologia, como se o fenômeno vital pudesse ser compreendido fora da trama histórico-social, cultural e política. Como se a vida, a pura vida, pudesse ser vivida de maneira igual em todas as suas dimensões na favela, no cortiço ou numa zona feliz dos "Jardins" de São Paulo. Se sou professor de biologia, obviamente, devo ensinar biologia, mas ao fazê-lo, não posso seccioná-la daquela trama (FREIRE, 1992, p. 41).
\end{abstract}

Reitero que a existência desse espaço de discussão nas universidades ou quaisquer outras instituições de ensino superior, a existência de núcleos e coletivos negros, é fundamental para a formação integral dos alunos, que vão atuar na sociedade e necessitam conhecer a diversidade que a rodeia, se reconhecer como uma pessoa diversa. As discussões sobre racismo, a conscientização sobre o mesmo no ensino superior, que é ocupado majoritariamente por jovens, não é "mimimi" como dizem quando querem desmerecer as pautas das minorias, e o núcleo se constitui como um espaço de luta para (re)afirmar a existência e ocupação dos negros nesse ambiente ainda elitista.

Por fim, apresento algumas inquietações: os profissionais que estão se formando no ensino superior estão sendo protagonistas na sua formação e construindo de fato suas identidades (profissional e pessoal)? Ou estão sendo moldados para serem mais uma peça no sistema que busca manter a estrutura social racista imposta? Que tipo de profissional estão se formando? Ademais, que tipo de profissionais almejamos ser?

Artigo recebido em: 01/03/2021

Aprovado para publicação em: 14/10/2021

THE CONSTRUCTION OF BLACK PROTAGONISM: THE IMPORTANCE OF NÚCLEO AFRO-BRASILEIRO E INDIGENA DE ILHA SOLTEIRA (NABISA) IN THE FORMATION OF A BIOLOGIST

ABSTRACT: The number of black people with access to higher education has increased in recent years, reflecting the growth of people who declare themselves black and brown due to social and political changes in recent decades. However, racism is still strongly present in different spheres of society, including higher education institutions. With this in mind, this article aims to reflect on how participation in NABISA impacted the construction of black protagonism in the formation of a Biologist based on the author's own narratives. The lack of approach to the black theme in graduation places NABISA as one of the main influences in the construction of the author's 
identity as a black and professional woman, demonstrating the importance of having spaces for social and political criticism and reflection that impact initial education.

KEYWORDS: Black Nucleus. Higher Education. Racism. Biology.

LA CONSTRUCCIÓN DEL PROTAGONISMO NEGRO EN LA FORMACIÓN DE UN BIÓLOGO: LA IMPORTANCIA DEL NÚCLEO AFRO-BRASILEIRO EINDIGENA DE ILHA SOLTEIRA (NABISA)

RESUMEN: El número de personas negras con acceso a la educación superior ha aumentado en los últimos años, lo que refleja el crecimiento de personas que se declaran negras y morenas debido a los cambios sociales y políticos de las últimas décadas. Sin embargo, el racismo sigue estando muy presente en diferentes ámbitos de la sociedad, incluidas las instituciones de educación superior. Con eso en mente, este artículo tiene como objetivo reflexionar sobre cómo la participación en NABISA impactó la construcción del protagonismo negro en la formación de un Biólogo a partir de las propias narrativas del autor. La falta de abordaje de la temática negra en la graduación coloca a NABISA como una de las principales influencias en la construcción de la identidad de la autora como mujer negra y profesional, demostrando la importancia de contar con espacios de crítica y reflexión social y política que impacten en la educación inicial.

PALABRAS CLAVE: Núcleo Negro. Educación Superior. Racismo. Biología.

NotA

1 - O presente artigo é fruto do Trabalho de Conclusão de Curso da primeira autora e foi construído em diálogo com seu orientador, segundo autor, e sua coorientadora, terceira autora. No entanto, por se tratar de uma narrativa, os trechos que se referem à experiência da autora serão apresentados na primeira pessoa do singular, evidenciando sua perspectiva a respeito de sua formação, enquanto uma mulher negra, no curso de bacharelado em Ciências Biológicas.

\section{REFERÊNCIAS BIBLIOGRÁFICAS}

ALMEIDA, S. L. de. O que é racismo estrutural? Belo Horizonte (MG): Letramento, 2018. $204 \mathrm{p}$.

AZEVEDO, C. M. M. de. Onda Negra, Medo Branco: O Negro no Imaginário das Elites Século XIX. Rio de Janeiro, Paz e Terra, 1987. 267 p.

ARIAS-CARDONA, A.; ALVARADO-SALGADO, S. Investigación narrativa: apuesta metodológica para la construcción social de conocimientos científicos. p. 171-181. 
SILVA, M. A.; GONÇALVES, H. J. L.; BONI, B. R.

Revista CES Psicología, v. 8, n. 2, 2015. Disponível em:

https://www.redalyc.org/pdf/4235/423542417010.pdf. Acesso em: 28 dez. 2020.

BARROS, S. A. P de. Discutindo a escolarização da população negra em São Paulo entre o final do século XIX e início do XX. In: ROMÃO, J. (org.). História da Educação do Negro e outras histórias. Secretaria de Educação Continuada, Alfabetização e Diversidade. Brasília: Ministério da Educação, Secretaria de Educação Continuada, Alfabetização e Diversidade. 2005. p. 79-92. Disponível em:

http://etnicoracial.mec.gov.br/images/pdf/publicacoes/historia_educacao_negro.pdf. Acesso em: 28 dez. 2020.

BETHENCOURT, F. Racismos:Das Cruzadas ao século XX / Francisco Bethencourt; tradução Luís Oliveira Santos. João Quina Edições. - $1^{\text {a }}$ ed. - São Paulo: Companhia das Letras, 2018. 592 p.

BOLSANELLO, M. A. B. Darwinismo social, eugenia e racismo "científico": sua repercursão na sociedade e na educação brasileiras. Educar em Revista, n. 12. Curitiba: Editora da UFPR. p. 153-165. 1996. Disponível em: https://www.scielo.br/pdf/er/n12/n12a14.pdf. Acesso em: 24 fev. 2021.

BRASIL. LEI N 10.639, DE 9 DE JANEIRO DE 2003: Altera a Lei no 9.394, de 20 de dezembro de 1996, que estabelece as diretrizes e bases da educação nacional, para incluir no currículo oficial da Rede de Ensino a obrigatoriedade da temática "História e Cultura Afro-Brasileira", e dá outras providências. Brasília: Casa Civil, 2003. Disponível em: http://www.planalto.gov.br/ccivil_03/_ato2007-2010/2008/lei//1 1645.htm. Acesso em: 09 fev. 2021.

BRASIL. LEI No 11.645, DE 10 MARÇO DE 2008: Altera a Lei no 9.394, de 20 de dezembro de 1996, modificada pela Lei no 10.639, de 9 de janeiro de 2003, que estabelece as diretrizes e bases da educação nacional, para incluir no currículo oficial da rede de ensino a obrigatoriedade da temática "História e Cultura Afro-Brasileira e Indígena". Brasília: Casa Civil, 2008. Disponível em: http://www.planalto.gov.br/ccivil_03/_ato20072010/2008/lei/l11645.htm. Acesso em: 09 fev. 2021.

BRASIL. MINISTÉRIO DA EDUCAÇÃO. AÇÕES AFIRMATIVAS. Brasília: MEC, 2021. Disponível em: http://etnicoracial.mec.gov.br/acoes-afirmativas. Acesso em: 19 fev. 2021.

FREIRE, P. Pedagogia do oprimido. 17a. ed. Rio de Janeiro: Paz e Terra, 1987. Disponível em: https://cpers.com.br/wp-content/uploads/2019/10/Pedagogia-do-Oprimido-PauloFreire.pdf. Acesso em: 09 fev. 2021.

FREIRE. P. Pedagogia da Esperança: Um Reencontro com a Pedagogia do Oprimido. Notas: Ana Maria Araújo Freire. Rio de Janeiro: Paz e Terra, 1992. Disponível em: https://www.finom.edu.br/assets/uploads/cursos/categoriasdownloads/files/201906282 10617.pdf. Acesso em: 18 out. 2021. 
HAMILTON, C. V; KWANE, T. Black Power: Politics of Liberation in America. Nova York: Random House, 1967. [Kindle Android version]. Acesso em: 09 fev. 2021.

IBGE - INSTITUTO BRASILEIRO DE GEOGRAFIA E ESTATÍSTICA. Síntese de indicadores sociais: uma análise das condições de vida da população brasileira:2020. Coordenação de População e Indicadores Sociais. - Rio de Janeiro : IBGE, 2020. 148 p. Disponível em: https://biblioteca.ibge.gov.br/visualizacao/livros/liv101760.pdf. Acesso em: 28 dez. 2020.

IPEA - INSTITUTO DE PESQUISA ECONÔMICA APLICADA. Atlas da violência 2020. Brasília: IPEA, 2020. Disponível em: https://www.ipea.gov.br/atlasviolencia/download/24/atlas-da-violencia-2020. Acesso em: 20 fev. 2021.

MEDEIROS, C. S. A de. Dialogando sobre o racismo para a aplicação da lei 10.639/03 no cotidiano escolar. In: SILVA, K. R. X. P. da; AMPARO, F. V. da S. do. (Org.). Criatividade e Interculturalidade, volume 1. - Curitiba: CRV, 2015. p. 79-87. Disponível em: http://criatividadeeensino.com.br/uploads/7/5/4/1/75419527/livrocompleto_criatividad e_e_interculturalidade_2015_final.pdf\#page=80. Acesso em: 13 fev. 2021.

NASCIMENTO, A do. O negro revoltado. Rio de Janeiro: GRD, 1968.

PELLANDA, N. M. C.; BOETTCHER, D. M. O esgotamento do paradigma clássico e a emergência da Complexidade. In: PELLANDA, N. M. P.; BOETTCHER, D.; MEIRA, M. P. (Org.). Viver/conhecer na perspectiva da complexidade - Experiências de pesquisa. 1. ed. Santa Cruz do Sul: EDUNISC, 2017. Disponível em: https://repositorio.unisc.br/jspui/bitstream/1 1624/1760/1/Viver\%20conhecer\%20na\%20 perspectiva\%20da\%20complexidade.pdf. Acesso em: 11 fev. 2021.

SALES, A. de J.; PASSO, J. J. R. Educação uma questão de cor: a trajetória educacional dos negros no Brasil. Brasil Escola, 2020. Disponível em: https://meuartigo.brasilescola.uol.com.br/educacao/educacao-questao-cor-trajetoriaeducacional-dos-negros-brasil.htm. Acesso em: 11 jan. 2021.

SILVA, G. da; ARAÚJO, M. Da interdição escolar às ações educacionais de sucesso: escolas dos movimentos negros e escolas profissionais, técnicas e tecnológicas. In: História da Educação do Negro e outras histórias. Organização: Jeruse Romão. Secretaria de Educação Continuada, Alfabetização e Diversidade. - Brasília: Ministério da Educação, Secretaria de Educação Continuada, Alfabetização e Diversidade. 2005. Disponível em: http://etnicoracial.mec.gov.br/images/pdf/publicacoes/historia_educacao_negro.pdf. Acesso em: 18 out. 2021.

SILVA, J. A. N da. Descrevendo 32 voltas ao redor de Rá: fragmentos de experiências vivenciadas por um biólogo negro desde sua graduação em 1982/1986 à sua 
SILVA, M. A.; GONÇALVES, H. J. L.; BONI, B. R.

titularidade em 2018. Revista da ABPN., v. 12, n. 31. 2020. p. 336-36. Disponível em: https://abpnrevista.org.br/index.php/site/article/view/779/770. Acesso em: 18 out. 2021.

SILVA. P. V. B. da,. O silêncio como estratégia ideológica no discurso racista brasileiro. Currículo sem Fronteiras, v. 12, n. 1, 2012. p. 110-129. Disponível em: https://pt.scribd.com/document/363288857/O-SILE-NCIO-COMO-ESTRATE-GIA-IDEOLOGICA-NO-DISCURSO-RACISTA-BRASILEIRO\#download. Acesso em: 18 out. 2021.

SILVA, T. D. Ação afirmativa e população negra na educação superior: acesso e perfil discente. Texto para discussão / Instituto de Pesquisa Econômica Aplicada. Brasília: Rio de Janeiro: Ipea, 2020. Disponível em:

https://www.ipea.gov.br/portal/images/stories/PDFs/TDs/td_2569.pdf. Acesso em: 12 jan. 2021.

SOARES, S. A demografia da cor: a composição da população brasileira de 1890 a 2007. In: THEODORO, M. (Org.). As políticas públicas e a desigualdade racial no Brasil: 120 anos após a abolição. Brasília: Ipea, 2008. Disponível em: https://www.ipea.gov.br/portal/images/stories/Livro_desigualdadesraciais.pdf. Acesso em: 12 jan. 2021.

VIÇOSA, R.; COSTA, A. R.; PINTO, M. M.; PICCININ, F. Q. Autonarrativas como método de pesquisa: sobre a complexidade de narrar-se. Jornada Acadêmica, v. 1, n. 1, 2019. Disponível em: https://online.unisc.br/acadnet/anais/index.php/jornacad/article/view/19455/11926121 74. Acesso em: 11 fev. 2021.

Márla AliXANdre Silva: Licenciada em Ciências Biológicas pela Faculdade de Engenharia de llha Solteira da UNESP. Atuou como monitora das disciplinas Metodologia Científica e História e Filosofia da Educação, como voluntária dos Projetos de Extensão Parque de Equoterapia, InterRobótica e InterCiência. Desenvolveu projeto que investigou aspectos relativos à Reforma do Ensino Médio.

Orcid: https://orcid.org/0000-0001-6587-5172

E-mail:marla.alixandre@unesp.br

Harryson Júnio LesSA GonçALVES: Livre-docente em Didática e Currículo (2019) pela Universidade Estadual Paulista - UNESP; doutor em Educação Matemática (2012) pela Pontifícia Universidade Católica de São Paulo - PUC/SP; pedagogo (2002) e mestre em Educação (2005) pela Universidade de Brasília - UnB.

Orcid: https://orcid.org/0000-0001-5021-6852

E-mail: harryson.lessa@unesp.br

Bianca Rafaela Bonl: Licenciada em Ciências Biológicas pela Faculdade de Engenharia da Universidade Estadual Paulista "Júlio de Mesquita Filho" (UNESP) - campus de llha 
Solteira. Mestra e Doutoranda pelo Programa de Pós-Graduação em Educação para Ciência da Faculdade de Ciências da UNESP, campus de Bauru.

Orcid: https://orcid.org/0000-0003-4765-4282

E-mail: bianca.boni@unesp.br

Este periódico utiliza a licença Creative Commons Attribution 3.0, para periódicos de acesso aberto (Open Archives Initiative - OAI). 